Archived version from NCDOCKS Institutional Repository http://libres.uncg.edu/ir/asu/

\title{
Appalachlyan
}

B O O N E, NORT H C A R O L N A

\section{The Impact Of Social Influence, Information Quality And Online Forum Features On The Credibility Of Doctors And Hospitals For Medical Tourism Services}

\author{
By: Charlie C. Chen, Makoto Nakayama, and Peter Ractham
}

\begin{abstract}
Medical tourism, especially cosmetic surgery to South Korea, is increasingly popular amongst Thai youths. Like many other youths around the world, they can obtain the relevant information from a variety of sources, including web discussion forums. These are the most frequently used information sources that people use to explore the feasibility of having cosmetic surgery overseas. However, it is not empirically clear how much influence these forums have on youth, or what impact social influence, the quality of information and the forum's features (e.g., doctor information, before/after surgery pictures, clinic/hospital information, surgery information and chat rooms) have on the credibility of doctors and hospitals. This study conducted a number of field experiments andcollected data from 233 discussion threads on top 3 online discussion forums that were ranked by 207 business school students. The results show that the reliability of web information is critical in enhancing the credibility of both doctors and hospitals. In addition, the credibility of doctors depends on the forum that is used to find information about surgery, as well as social influence. The credibility of hospitals, on the other hand, is not influenced by the social influence of a consumer's peers. Instead, their credibility is increased by the forum's use of before/after surgery pictures, clinical information and information about doctors. Future research may investigate further how different forum features and the web media can have an impact on the credibility of doctors and hospitals.
\end{abstract}

Chen, C. C., Nakayama, M., \& Ractham, P. (2015). The Impact of Social Influence, Information Quality and Online Forum Features on the Credibility of Doctors and Hospitals for Medical Tourism Services. International Journal of Healthcare Information Systems and Informatics (IJHISI), 10(4), 22-37. doi:10.4018/IJHISI.2015100102. Publisher version of record available at: https://www.igi-global.com/article/the-impact-of-social-influence-information-qualityand-online-forum-features-on-the-credibility-of-doctors-and-hospitals-for-medical-tourism-services/149245 


\title{
The Impact of Social Influence, Information Quality and Online Forum Features on the Credibility of Doctors and Hospitals for Medical Tourism Services
}

Charlie C. Chen, Walker College of Business, Appalachian State University, Boone, NC, USA Makoto Nakayama, College of Computing and Digital Media, DePaul University, Chicago, IL, USA

Peter Ractham, Thammasat Business School, Thammasat Universtiy, Bangkok, Thailand

\begin{abstract}
Medical tourism, especially cosmetic surgery to South Korea, is increasingly popular amongst Thai youths. Like many other youths around the world, they can obtain the relevant information from a variety of sources, including web discussion forums. These are the most frequently used information sources that people use to explore the feasibility of having cosmetic surgery overseas. However, it is not empirically clear how much influence these forums have on youth, or what impact social influence, the quality of information and the forum's features (e.g., doctor information, before/after surgery pictures, clinic/hospital information, surgery information and chat rooms) have on the credibility of doctors and hospitals. This study conducted a number of field experiments and collected data from 233 discussion threads on top 3 online discussion forums that were ranked by 207 business school students. The results show that the reliability of web information is critical in enhancing the credibility of both doctors and hospitals. In addition, the credibility of doctors depends on the forum that is used to find information about surgery, as well as social influence. The credibility of hospitals, on the other hand, is not influenced by the social influence of a consumer's peers. Instead, their credibility is increased by the forum's use of beforelafter surgery pictures, clinical information and information about doctors. Future research may investigate further how different forum features and the web media can have an impact on the credibility of doctors and hospitals.
\end{abstract}

Keywords: $\quad$ LeastLikelihoodModel(ELM), Medical Tourism, Online Decision-Making, Online Information Search, Self-Perception Theory, Trust in Online Information 


\section{INTRODUCTION}

Medical tourism is the movement of patients across borders in the pursuit of cost-effective medical treatment and health, according to OIED (Lunt, 2011). It is fast becoming a new international business trend because of its attractiveness to tourists who need cost-effective medical services. For instance, spinal surgery costs a patient about $\$ 70,000$ in the U.S., but the same procedure, plus a five-day stay in a private room, would cost only $\$ 4,700$ in a reputable international hospital in Bangkok, Thailand (Smith, 2012). The greater the price difference between these care services in home and foreign country, the more likely it is that medical tourism services will thrive. Cosmetic surgery, dentistry and orthopaedics are among the most popular services proactively sought by American patients. This is a 100-billion dollar industry and there are currently about 20 million medical tourists who account for $2 \%$ of world tourism and $4 \%$ of hospital admissions in the world (Andio Freire, 2012).

Asian countries, such as India, the Philippines, South Korea and Thailand, enjoy a competitive price advantage and so are emerging as popular destinations for medical tourism (Yu and Ko, 2012). Having medical treatment in Asia can save a person up to $33 \%$ in costs, compared to the U.S. (Mun and Musa, 2012). The medical tourism industry in Asia is expected to reach $\$ 8.5$ billion by 2013 (Global Information, 2012). South Korea has the highest per capita cosmetic procedures in the world in 2010 and is one of the leading destinations for cosmetic surgery from overseas (Economist Online, 2012). According to the International Society of Aesthetic Plastic Surgery (ISAPS), people from those Asian nations are also the top consumers of cosmetic surgeries in the world (ISAPS, 2011).

Apart from these cost advantages, medical tourism poses some unique challenges for consumers because of the healthcare regulatory and legal concerns across borders (Terry, 2007) that create both geographical and psychological distances between consumers and healthcare provider locations (Zhang, Seo and Lee, 2013). Given these challenges, consumers rely on information that is available on the web. In general, more than $80 \%$ of internet users are turning to online health information forums for answers to their questions before taking any concrete action (Fox, 2006).

Although online health forums are proliferating, it is uncertain whether they are an effective medium for consumers and healthcare service providers. Firstly, the identity of forum posters is often not fully disclosed. Secondly, descriptions of patient experience may not be comprehensive and can miss out some critical information. Thirdly, reviews of doctors and hospitals can be biased, as highly satisfied or dissatisfied patients post them. Fourthly, it is unclear how much social influence and other factors have an impact on the use of online discussion forums and if this affects the intention of users to adopt medical tourism services. Fifthly, medical tourists often express anxiety about receiving medical tourism services from a foreign doctor in a foreign facility. Increasingly, the impact that online discussion forums have on the credibility of doctors and hospitals may play an important role in the decision that prospective medical tourists make.

Credibility is defined as "[t]he belief that the other party is honest, reliable, and competent" (Ba and Pavlou, 2002, p. 246). It is still not known whether online discussion forums, and in particular their features, can help to increase the credibility of hospitals and doctors, thereby influencing the intention of users to purchase medical tourism services. Faced by the popularity of overseas cosmetic surgery and the uncertainty of online information, this paper aims to address research questions that are related to the last two challenges, which are associated with online medical tourism forums. Specifically, this study will examine the credibility of hospitals and doctors and assess how sixteen forum features could have an impact on them. These features are: an activity room, users asking questions about their concerns, discussion forums, an exchanging knowledge room, FAQs, information about the hospital, information about the doctor, general information about Korean cosmetic surgery, information about Korean cosmetic surgery pro- 
cedure, general information about Thai cosmetic surgery, information about the tour package, promotions for clinics, review pictures before and after surgery, a room to sell cosmetics and clothing, hot issues and the top 10 members.

The following discussion will first review the literatures that relate to the key factors that affect the credibility of hospitals and doctors. Secondly, the research methodology will be clarified with regard to data collection and analysis methods. Thirdly, academic and practical implications will be drawn from the findings. Finally, this study will conclude with a discussion about both the direction and limitations of the research.

\section{THEORETICAL BACKGROUND}

\section{Online Healthcare Information}

The popularity of search engines and portable devices has fuelled the use of online information searches over the past decade. In 2005, about two-third of adults were already seeking some types of healthcare information for themselves or their peers (Hesse et al., 2005). Although consumers rely on the web, some healthcare professionals are seriously concerned about the quality of online information (Morahan-Martin, 2004). The problem with the internet is not necessarily a lack of information, but the abundance of incomplete information. This is, in some cases, misleading or inaccurate and can vary widely in quality (G Eysenbach, Powell, Kuss and Sa, 2002; Silberg, Lundberg and Musacchio, 1997). However, "half of those who have sought health information online in the United States reported these materials affected their decisions about treatment and care" (ibid., p. 499).

The supply side of healthcare information should not bear all of the blame. For example, despite the abundance of information, there is little consistency in how consumers expect, seek, find and use online healthcare information (Cotten and Gupta, 2004). In addition, many consumers do not read beyond the first page of their search results (Morahan-Martin, 2004) and are "seldom diligent" in checking and validating the information they obtain online (Metzger, 2007). Indeed, online information can prove to be advertisements, fraudulent, outdated and/or sourced by unqualified parties. Metzger (2007) thus suggests 25 guidelines to assess the credibility of online healthcare information.

\section{Decision-Making Regarding Cosmetic Surgery Overseas}

Consumers should not only browse healthcare information online, but also use the web to make their healthcare decisions. The Pew Research Center reports in its recent survey that $59 \%$ of U.S. adults explore the internet to gather health diagnostic information (Painter, 2013). About $35 \%$ of U.S. adults use the web even to diagnose themselves, although $70 \%$ indicate they have sought professional help for a serious health concern (ibid.). However, there are some cultural differences when it comes to searching for online healthcare information and subsequent decisionmaking. For example, $17 \%$ of Japanese people look for information on the web only after it has been suggested to them by their doctor, while adults in the U.S. and Germany frequently make the decision to seek online healthcare information by themselves.

Given the variations that exist in the quality of information, consumer expectations and cultural differences, how can we model consumers' healthcare decision-making? A few studies have proposed a generic model that is relevant for the credibility of healthcare information and making a judgment over the web. The first model (Briggs, Burford, De Angeli and Lynch, 2002) shows that the probability of consumers taking advice online is influenced by three factors: the credibility of the source, whether the advice is personalised and the consistency and 
predictability of that advice. The second model (Briggs, Simpson and Angeli, 2004) is based on an observation that consumers generally visit many websites to scan information with some heuristics. They then evaluate the website and information systematically in order to integrate all of the information and start long-term trusting relations with a few select websites. The third model (Metzger, 2007) divides online information use into three phases. The first is the exposure phase, where consumers' motivation and their ability to evaluate the website play critical roles. The next, evaluation phase consists of either no evaluation, heuristic/peripheral evaluation or thorough, systematic evaluation. If the evaluation is positive, consumers then enter into the judgment phase to critically assess the credibility of the website and whether to trust its information or not. Extant studies regard trust as a composite of two elements: credibility and benevolence (Dimoka, 2010). Benevolence refers to "[t]he belief that one partner is genuinely interested in the other partner's welfare" (Ba and Pavlou, 2002, p. 246). Because this study focuses on how prospective patients believe in doctors and hospitals, we mainly focus on the credibility aspect of trust when referring to trust in the following sections.

\section{Information Credibility of Online Discussion Forums}

Information credibility of healthcare websites depends on several major factors. Numerous studies (Bates, Romina, Ahmed and Hopson, 2006; G. Eysenbach et al., 1998; O'Grady, Betel and Shachak, 2010) have noted the importance of information credibility, given that a decision is based on information that can lead to either significant positive or negative health and financial implications. Judging whether information is credible or not, however, is a fundamental conundrum for consumers. The fact that they are not an expert to make this kind of judgment means many healthcare experts advise consumers to consult with them (Torpy, Burke and Golub, 2011). As an example, in one study (Gordon, Barot, Fahey and Matthews, 2001) three experienced cosmetic surgeons assessed the results of a web search by using the term "breast augmentation". Their evaluations found that some websites offered limited, accurate procedural details, but no website was perfect. We therefore have to wonder whether the average consumer can discern the accuracy and relevancy of website contents as much as these three experts did.

The design and contents of healthcare websites have a significant impact on their credibility levels (Sillence, Briggs, Fishwick and Harris, 2004; Sillence, Briggs, Harris and Fishwick, 2007). For example, consumers will have a favourable impression of a website if its layout is clear with adequate navigational aids. Interactive features, such as assessment tools, will also enhance a website's credibility. The site's contents, such as how informative it is, its use of illustrations, its content biases and language clarity, are also important. Comparisons of 57 medical facilitator websites have shown that the site content structures and the emphasis of websites are different in Asia, Europe, the central and South America and North America (Cormany and Baloglu, 2011). Such differences are not surprising as consumer needs, regulations and healthcare infrastructures vary from nation to nation. As a result, healthcare providers adjust their website's contents accordingly.

The above review points us to a few critical issues. Firstly, there are variations in the quality of online healthcare information. Secondly, consumers use some triangulation in order to judge which websites are more trustworthy than others. Thirdly, it is basically up to consumers to decide what information is credible and how they should use it. For those who are considering cosmetic surgery overseas, is their trust in hospitals and doctors influenced by the information they find on online forums? Also, how does the perceived credibility of doctors and hospitals have an impact on the user's decision to have surgery? The next section proposes a conceptual model and hypotheses that will address these questions. 


\section{HYPOTHESES}

Faced with abundant online information, how do consumers perceive the credibility of different features of online discussion forums, hospitals and doctors? The literature reviews reveal that it is up to consumers how to navigate the information on forums and to both find and screen credible information. After considering how forums can help users to make decisions about receiving medical care overseas, we identified three key variables that influence whether the information on online discussion forums is seen as credible. As many users heavily rely on information posted on discussion forums to learn about the credibility of hospitals and doctors offering care abroad, it is important to understand the impact of reliable information on forums, including the different uses of forums (e.g. searching for information about doctors and surgeries) and social influence on the perceived credibility of doctors and hospitals.

\section{Perceived Credibility of Information on Online Discussion Forums}

The first variable we focused on was the users' confidence and self-belief about the credibility of the information that they searched for and found on discussion forum. Self-Perception Theory (Bem, 1972) posits that consumers can form their own attitudes, beliefs and feelings by observing their own behaviour. That is, consumers who engage in online searching and discussions on forums tend to believe in their ability to search and identify relevant information on medical tourism online. For example, a study showed that the height and attractiveness of an avatar in an online game predicted the performance of the players and influenced their subsequent face-toface interactions (Yee, Bailenson and Ducheneaut, 2009). This is akin to self-fulfilling prophecy (Biggs, 2009). Those who are confident about obtaining information online do find the relevant medical tourism information and also trust online discussion forums that they find relevant, useful and credible. This aspect is critical because no one usually supervises consumers or shows them how to look for relevant information on the web. In most cases, it is left entirely up to consumers themselves to find online information. When users are confident that the information they locate on forums is reliable, they are more likely to trust these forums to perform medical tourism services. Therefore, we hypothesise:

H1a: If information on the forums is perceived to be credible, this will have a positive effect on medical tourists and they will perceive the doctors to be credible as a result.

H1b: If information on the forums is perceived to be credible, this will have a positive effect on medical tourist and they will perceive hospitals to be credible as a result.

\section{Influence of One's Close Peers}

The second variable has an influence on not only the credibility of information, but also on consumer decision-making. The basic dilemma for consumers is that they can search online as much as they want, but they do not have the complete information or the professional expertise they need to decide what information is credible and trustworthy. According to the elaboration likelihood model (Bhattacherjee and Sanford, 2006; Petty and Cacioppo, 1986), consumers tend to go with the "peripheral route", which means they are persuaded to make a purchase decision when they cannot approach the decision rationally due to incomplete, inaccurate and/or non-trustworthy information. A recent study (Nakayama, Wan and Sutcliffe, 2011) noted that traditional wordof-mouth (WOM) is still more powerful and influential than electronic WOM (e.g. eWOM or opinions rumours and reviews by other consumers online who are strangers to the consumer) or 
even expert opinions. The reason behind this is that online information is frequently anonymous and so consumers are uncertain as to its credibility and source(s). In contrast, consumers feel reassured by face-to-face (F2F) communication with someone that they know (e.g., WOM).

F2F communication is considered to be the most efficient way of building trust (Nohira and Eccles, 1992) because it is able to enforce social similarity, shared values and provide immediate feedback (Jarvenpaa and Leidner, 1999). However, medical tourists can find this rich communication channel ineffective because they may not want their families and close friends to know about the planned treatment and fear they will interfere in the process. In addition, they may not be the best people to speak to, since they may not have had the same experience. The best people to talk to could be those who have either received, or plan to receive, similar treatments in the same facility and in the same country (Smith, 2012; Johnston, Crooks and Snyder, 2012). When interpersonal trust is absent from the F2F context, consumers can look to prospective, existing and past patients in online discussion forums as natural candidates with whom they can build interpersonal trust.

As they share the same background, members in online discussion forums are more willing to open up to each other (Brown, Poole and Rodgers, 2004). The interaction among forum members can help to generate highly credible information because it is based on the extensive experiences of all the participant members (Peppers and Rogers, 1997). Doing this can help to encourage prospective patients to take the surgery, making them feel less reserved and also improve their conversations with people who have had the same condition (Paul and McDaniel, 2005). Leveraging the capability of online discussion forums to improve interpersonal trust between patients can potentially benefit many medical tourists by helping them to become better prepared to begin their journey. Therefore, we propose:

H2a: The users' expectations of their peers' opinions on the usefulness of online discussion forums has a positive effect on the perceived credibility of doctors on online discussion forums.

H2b: The users' expectations of their peers' opinions on the usefulness of online discussion forums has a positive effect on the perceived credibility of hospitals on online discussion forums.

\section{Online Forum Features}

System trust is as important as interpersonal trust to members of online discussion forums. It is particularly important to help virtual communities, such as online discussion forums, shape both the culture and norms in the early stages (Blanchard and Markus, 2004). System trust can be increased by improving the navigability, aesthetics, graphic design and user-friendliness of websites (Fogg et al., 2002). On the other hand, conversations between members may be disrupted constantly if the system's reliability is poor, especially if all the information posted on an online discussion forum is not archived or is difficult to find.

As we saw in the literature review, features on the websites of healthcare providers and facilitators can have a positive impact on consumer trust. Metzger (2007) suggests that consumers should pay attention to information source citations, contact information, professional site designs and sponsorship by reputable organisations, interactive features and the relevancy and comprehensiveness of the information found. The success of an online community, including member participation and attachment, depends on a group identity and interpersonal bonds being built amongst its members (Ren et al., 2012). A growing number of medical tourists are using online discussion forums in order to increase both their interpersonal bonds with others and their perceived trust in the hospital and doctor before taking action. 
Information posted by other medical tourists regarding the perceived level of service the medical service provides can affect the expectations of prospective patients about the service (Guiry and Vequist, 2011). Before making the final decision to go for medical care abroad, prospective patients primarily rely on the testimonials of former medical tourists and wordof-mouth opinions, rather than advice given by family physicians or third-party information sources (Johnston, Crooks and Snyder, 2012). Online discussion forums are a platform that former medical tourists can use to share their testimonials and personal opinions about the hospital and doctor they received treatment from. If medical tourists trust the information that is shared by others about the hospital and doctor on the forum, they are more likely to trust the recommended hospital or doctor.

In addition to this testimonial feature, past studies have shown that the site's design can increase customer loyalty and improve the credibility of both e-commerce (Flavián, Guinalíu and Gurrea, 2006; Shankar, Urban and Sultan, 2002) and m-commerce (Cyr, Head and Ivanov, 2006). Online discussion forums contain many other features, which can be leveraged to increase the credibility of doctors and hospitals on online forums. These features include activity rooms, the opportunity for consumers to ask questions about their concerns, discussion forums, an exchanging knowledge room, FAQs, information about the hospital, information about the doctor, general information about Korean cosmetic surgery and cosmetic surgery procedure, general information about Thai cosmetic surgery, information about the tour package, promotions from the clinic, review pictures of before and after surgery, a room to sell cosmetic and clothing, hot issues and the top 10 members. These features can have different degrees of impact on the credibility of the doctor and hospital on the forums. Therefore, we propose:

H3: The use of different forum features has different degrees of positive influence on increasing the credibility of doctors on online discussion forums.

H4: The use of different forum features has different degrees of positive influence on increasing the credibility of hospitals on online discussion forums.

The above discussion leads to the following theoretical framework (Figure 1), which can help to promote an understanding of the key factors for the successful use of online discussion forums in order to improve the credibility of doctors and hospitals on online discussion forums, thereby increasing the intention of users to purchase medical tourists services overseas.

\section{METHOD}

The websites we focused on offer cosmetic surgery information (CSI) by doctors, hospitals and past/prospective patients, who share their experiences and opinions on web forums. We call such websites CSI forums for short. These are typically set up and run by a third party, but they usually use some form of sponsorship from doctors and hospitals. To test the hypotheses, we used the two-step lab experiments (which took three hours each) followed by a survey questionnaire. We used the stepwise regression analysis in order to analyse the data in order to identify the subset of factors that can help to predict the perceived credibility of doctors and hospitals on online forums.

\section{Lab Experiments}

A total of 207 college students (144 females, 61 males, 2 unknowns), aged from 20 to 29-yearsold, participated in our experimental study, who were target customers for cosmetic surgery 
Figure 1. Theoretical framework

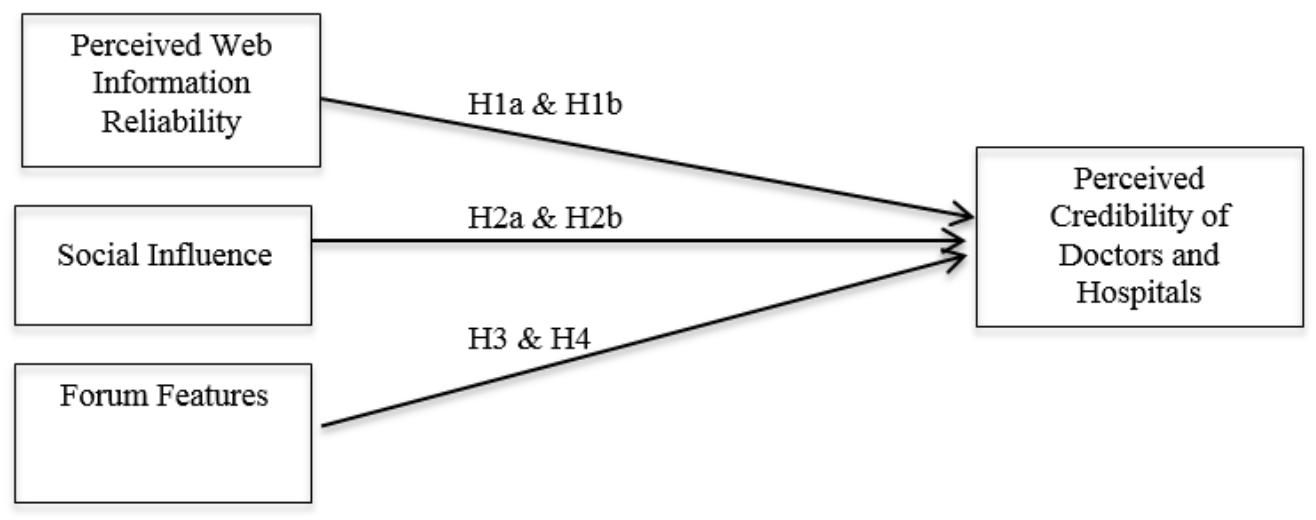

(Javo and Sørlie, 2009, Frederick, Lever and Peplau, 2007, Markey and Markey, 2009). The quality of information and technical features on CSI forums varies. The personal experiences and background of users may also affect the way that they perceive the information and technical quality of CSI forums. To minimise the potential influence of these factors, we designed a two-phase lab experiment. In the first phase, participants were asked to select the top three quality CSI forums, as well as three of the most popular discussion threads in these forums, after spending three hours browsing, reviewing and identifying the most popular CSI forums in Thailand. All of the participants were told to use the following four criteria to evaluate the quality of each CSI forum: 1) how complete the information was, 2) how clear the explanation of the plastic surgery procedures in South Korea were, 3) whether the information on Korean doctors and hospitals was credible, and 4) whether the discussion threads included the most informative shared experiences of past patients.

In the second phase, subjects were asked to participate in another three-hour lab experiment. All participants were divided into groups of three (one male and two females) to minimise the potential influence of gender. It was also critical to avoid participants having uneven knowledge levels of the subject matter. To minimise any biases that were associated with such an issue, we adopted the following procedures. After all the groups were formed, each group spent 3 hours thoroughly reading the three popular discussion threads and discussing amongst themselves how the information was presented and how they would make informed decisions regarding whether to have cosmetic surgery in South Korea. Once these two sessions (which took a total of six hours) were completed, they were asked to complete an online questionnaire.

\section{Variable Definitions}

Independent variables (IDVs) for the credibility of doctors and hospitals in online discussion forums included: web information reliability, social influence and forum features. Dependent variables (DV) included the credibility of doctors and hospitals on online forums. The following 16 forum features were identified: an activity room, users' asking questions about their concerns, discussion forums, an exchanging knowledge room, FAQs, information about the hospital, information about the doctor, general information about Korean cosmetic surgery, information about Korean cosmetic surgery procedure, general information about Thai cosmetic surgery, information about the tour package, promotions for the clinic, review pictures before and after 
surgery, a room to sell cosmetic and clothing, hot issues and the top 10 members. Each item was measured with a 5-point Likert scale on the frequency of use (from never to every time). Table 1 lists the multi-item variables we used for the survey questionnaire.

\section{RESULTS}

Two regression models were constructed with one dependent variable as the credibility of the doctor, and another one as the credibility of the hospital in online forums. The independent variables were the same for both regression models and included web information reliability, social influence, gender, experience of forum use, interest level and 16 forum features. We adopted the stepwise regression method in order to remove variables that were based on whether their coefficients were statistically significant. As a result of this approach, we were able to fine-tune our research models into:

\section{Refined Research Model 1}

The credibility of doctors on online forums $=$ web information reliability + social influence + forum use for doctor information + forum use for surgery information

\section{Refined Research Model 2}

The credibility of hospitals on online forums $=$ web information reliability + forum use for doctors information + forum use for hospital information + forum use for Thai surgery information + forum use for before/after pictures

Both models are significant with $\mathrm{F}_{(4,170)}=15.15, \mathrm{p}=0.000$ (Table 2) and $\mathrm{F}_{(5,170)}=4.75, \mathrm{p}=$ 0.000 (Table 3), respectively. First, the credibility of the doctor depends on the reliability of web information $(\beta=0.46, p=0.000)$, social influence $(\beta=-0.14, p=0.044)$, forum use for doctor information $(\beta=-0.28, p=0.010)$ and forum use for surgery information $(\beta=0.26, p=$ 0.017 ). These support H1a and $\mathrm{H} 2 \mathrm{a}$. $\mathrm{H} 3$ is also partially supported for the independent variables of forum use for doctor information, and forum use for surgery information.

Secondly, the credibility of the hospital is significantly influenced by the reliability of web information $(\beta=0.20, p=0.008)$ and forum use for Thai surgery information $(\beta=0.28, p=$ $0.029)$. In addition, other forum uses, such as before/after pictures $(\beta=-0.22, p=0.056)$, hospital information $(\beta=0.31, p=0.057)$, and doctor information $(\beta=-0.28, p=0.065)$ affect the level of

Table 1. Key variable constructs

\begin{tabular}{|l|l|c|l|}
\hline \multicolumn{1}{|c|}{ Variable } & \multicolumn{1}{|c|}{ Items and scale } & Cronbach $\boldsymbol{\alpha}$ & \multicolumn{1}{c|}{ References } \\
\hline $\begin{array}{l}\text { Web Information } \\
\text { Reliability }\end{array}$ & $\begin{array}{l}\text { 3 items, 7-point } \\
\text { Likert scale }\end{array}$ & 0.69 & $\begin{array}{l}\text { (McKnight, Choudhury and Kacmar, } \\
\text { 2002; Moorman, Deshpandé and Zaltman, } \\
\text { 1993) }\end{array}$ \\
\hline $\begin{array}{l}\text { Perceived Credibility of } \\
\text { Hospital \& Doctor }\end{array}$ & $\begin{array}{l}\text { 3 items each } \\
\text { 7-point Likert scale }\end{array}$ & $\begin{array}{l}0.75 \\
0.76\end{array}$ & $\begin{array}{l}\text { (Doney and Cannon, 1997; Sirdeshmukh, } \\
\text { Singh and Sabol, 2002) }\end{array}$ \\
\hline Social Influence & $\begin{array}{l}\text { 3 items, 5-point } \\
\text { Likert scale }\end{array}$ & 0.87 & (Venkatesh et al., 2003) \\
\hline
\end{tabular}


Table 2. Regression summary on the credibility of the doctor

\begin{tabular}{|l|l|l|}
\hline \multicolumn{1}{|c|}{ Dependent Variable } & \multicolumn{1}{|c|}{ Independent Variables } & \multicolumn{1}{c|}{ Beta } \\
\hline Credibility of Doctor & Web information reliability & 0.46 \\
\cline { 2 - 3 } & Social influence & -0.14 \\
\cline { 2 - 3 } & Forum use for doctors information & -0.28 \\
\cline { 2 - 3 } & Forum use for surgery information & 0.26 \\
\hline
\end{tabular}

Table 3. Regression summary on the credibility of the hospital

\begin{tabular}{|l|l|l|}
\hline \multicolumn{1}{|c|}{ Dependent Variable } & \multicolumn{1}{|c|}{ Independent Variables } & \multicolumn{1}{c|}{ Beta } \\
\hline Credibility of hospital & Web information reliability & 0.20 \\
\cline { 2 - 3 } & Forum use for Thai surgery information & 0.28 \\
\cline { 2 - 3 } & Forum use for before/after picture & -0.22 \\
\cline { 2 - 3 } & Forum use for hospital information & 0.31 \\
\cline { 2 - 3 } & Forum use for doctor information & -0.28 \\
\hline
\end{tabular}

hospital credibility. They support H1b. However, social influence is not a significant factor. Thus, $\mathrm{H} 2 \mathrm{~b}$ is not supported. H3 is partially supported for four independent variables, including forum use for Thai surgery information, before/after picture, as well as hospital and doctor information.

\section{Implications}

The first important finding of this study is that the credibility of both the doctor and hospital is directly affected by how reliable potential patients find information to be on the web. This means that consumers do read web information on overseas cosmetic surgery seriously. If the information on a forum is deemed to be unreliable, prospective patients tend to ignore it. On the other hand, they do take the information seriously if it is seen to be reliable, whether it is favourable or unfavourable for the doctors and hospitals.

The second notable finding was that prospective patients do use certain features of web forums to look for specific information. In Table 2, they used detailed information about surgery in order to assess how credible the doctors were. Yet, the influence of doctor information negatively impacts on the credibility of doctors, which is the opposite of what we had expected.

One participant said, "I felt very confident after I learned from the site about the doctors who has [sic] successful operations." Another participant also mentioned, "I like the site where they featured famous doctors who are all experts in their respected fields." Also, some gave credit to the website for having the discussion and information exchanges about the doctors' reputations through communication systems, such as chat rooms or doctor information discussion threads. A participant said, "I like the chatroom where I can discuss with others members about the reputation of any doctor I was interested in." Another participant noted that, "The doctor information room was very useful for me to browse through various doctors and their expertise." Thus, we tend to think that the information about doctors must have a positive influence on their credibility.

However, some participants wanted to speak to real people. One of them said: "I still want to talk to a real person or ex-patients who have had the surgery, because I will be more certain 
about the operations and hear the real stories from the people who have done the procedure." Therefore, prospective patients are looking for not so much information about doctors per se, but rather something that is a real story they can believe in or an experience that gives them credible details.

Regarding the credibility of hospitals, the influence of doctor information actually has a negative influence on hospital credibility. Instead, prospective patients look carefully at the details of a number of possible locations, from small clinics to large hospitals, before judging hospital credibility. A participant said, "I learned a lot about new technology in Korean hospitals, also they seems to have many customers from overseas. I am very interested in the service provided by them." Hence, it is pertinent for hospitals and doctors to have thorough, useful and up-to-date information, as well as some interactions with their potential customers in order to build up a high level of credibility.

Despite the serious nature of the information seeking behaviours of people thinking about cosmetic surgery, one interesting finding was the impact of showing a before/after picture of cosmetic surgery, which had a negative impact on the hospital's credibility. A possible explanation for this may be the effect of telling "honest" patient experiences. It seems that prospective patients want desired outcomes, but they are not necessarily eager to learn about the "whole" experience, in which some pain is involved and it proves to be less of a dream and more like reality.

Finally, the third important finding was that social influence was not a significant or even a negative factor in judging the credibility of doctors and hospitals. On the surface, it would seem that the strong influence of people close to prospective patients would encourage them to look harder for web information to assess the credibility of the hospital and doctor, but the results indicate that prospective patients are actually self-motivated (although external peer pressure or outside influences may hurt the credibility of the doctors and hospitals). During our lab experiment sessions, participants often remarked that some of the discussion threads looked like infomercials, and thus the information did not appear credible. They also indicated that they tended to believe the threads that included the real experiences of people who shared "real stories", rather than those that seemed to be tie-ins or commercialised information.

All of these findings affirmed that good information provided on medical tourism forums is useful in helping to assess the credibility of doctors and hospitals. However, just having "good" information is not enough. An effective online discussion forum is also needed to provide prospective patients with opportunities to interact with medical tourists who have had similar procedures from the same doctor and hospital. Other avenues that are useful in developing such social influence should be incorporated into online discussion forums. These avenues can include chat rooms and interactive discussion boards, where medical tourists can convey and exchange information whenever they need it from each other. Increasing the degree of social influence via online discussion forums would make it more likely that prospective patients purchase a medical tourism service. In addition, this study has contributed to a greater understanding of how modern business can evolve business models by using the internet to build credibility and trust, and providing valuable information and a better understanding of how e-commerce in the field of medical tourism can be exploited.

\section{LIMITATIONS AND FUTURE RESEARCH}

There are several limitations of this study. Firstly, the results reflect the perspective of people who are 20 to 29-years-old and live in Southeast Asia. This study mainly focuses on participants from Thailand who may be interested in getting cosmetic surgery in Korea. Since the Korean 
medical tourism industry also attracts various types of prospective patients from many other Asian countries, future research should also include prospective patients from other countries. Secondly, a central concept of the theoretical model is that perceptions of how easy it is to search for information on the CSI forums will have an impact on the credibility of these forums. CSI forums vary in many different ways, including their search capability, technical features, the characteristics of users and the various contents posted by users. These factors can influence the user's experience and affect their intention to use CSI forums. This study did not control and investigate these factors and their potential influence on the use of CSI forums, so future research may want to consider these factors for medical tourism studies. Thirdly, the results are based on what our survey participants considered to be credible and useful websites. Fourthly, some caution is due on how to generalise the above implications.

\section{CONCLUSION}

Medical tourism is a prevalent global healthcare practice that attracts millions of patients to quickly access quality care at an affordable price in another country. To compete in the global industry, many countries have dedicated resources in order to construct a medical tourism ecosystem, which involves hospitals, official agencies, tourism conduits, international regulation managers and referral services. Despite these efforts, most patients are not familiar with healthcare practices in another country. Consequently, they become anxious and lose interest in seeking medical care form a foreign medical service provider. This study examines the key features of online medical discussion forums and the potential impact that these online social forums have on the credibility of doctors and hospitals.

The results showed that prospective patients critically evaluated the reliability of information available on the web. They also tended to use a variety of features available on interactive discussion forums. This study found that they could both sense what the real story is and when the information is commercially motivated. In fact, the information about doctors had a negative impact on the credibility of doctors and hospitals. Prospective patients instead look for the details of surgical procedures, clinics/hospitals and how cosmetic surgeries are done locally in general. One surprising finding was the counter-effects of social influence. As cosmetic procedures are potentially costly and harmful, prospective patients searching for information and making assessments are primarily self-motivated.

Therefore, it is important that stakeholders, such as hospitals and doctors, who want to attract prospective patients must provide both useful information on their sites and a "personal touch", so that readers can gain necessary information from other experienced community members or past patients who have already had the operation and thus are deemed to be experts within the online community.

\section{ACKNOWLEDGMENT}

This research was partially funded by The Center of Excellence in Operations and Information Management, Thammasat University. 


\section{REFERENCES}

Andio Freire, N. (2012). The emergent medical tourism: Advantages and disadvantages of the medical treatments abroad. International Business Research, 5(2), 41-50.

Bates, B. R., Romina, S., Ahmed, R., \& Hopson, D. (2006). The effect of source credibility on consumers' perceptions of the quality of health information on the Internet. Informatics for Health \& Social Care, 31(1), 45-52. PMID:16754366

Bem, D. J. (1972). Self-Perception Theory. In L. Berkowitz (Ed.), Advances in Experimental Social Psychology (Vol. 6). New York: Academic Press.

Bhattacherjee, A., \& Sanford, C. (2006). Influence processes for information technology acceptance: An elaboration likelihood model. Management Information Systems Quarterly, 2006, 805-825.

Biggs, M. (2009). Self-fulfilling prophecies. In P. Hedström \& P. Bearman (Eds.), The Oxford handbook of analytical sociology (pp. 294-314). New York: Oxford University Press.

Blanchard, A.L., Markus, M.L. (2004). The experienced "sense" of virtual community: characteristics and processes. The DATABASE for Advances in Information Systems, 35(1).

Briggs, P., Burford, B., De Angeli, A., \& Lynch, P. (2002). Trust in online advice. Social Science Computer Review, 20(3), 321-332. doi:10.1177/089443930202000309

Briggs, P., Simpson, B., and Angeli, A. (2004). Personalisation and trust: a reciprocal relationship? In Designing Personalized user experiences in eCommerce (pp. 39-55).

Brown, H. G., Poole, M. S., \& Rodgers, T. L. (2004). Interpersonal traits, complementarity, and trust in virtual collaboration. Journal of Management Information Systems, 20(4).

Cormany, D., \& Baloglu, S. (2011). Medical travel facilitator websites: An exploratory study of web page contents and services offered to the prospective medical tourist. Tourism Management, 32(4), 709-716. doi:10.1016/j.tourman.2010.02.008

Cotten, S. R., \& Gupta, S. S. (2004). Characteristics of online and offline health information seekers and factors that discriminate between them. Social Science \& Medicine, 59(9), 1795-1806. doi:10.1016/j. socscimed.2004.02.020 PMID:15312915

Cronbach. (1951). Coefficient alpha and the internal structure of tests. Psychometrika, (16), 297-334.

Cyr, D., Head, M., \& Ivanov, A. (2006). Design aesthetics leading to m-loyalty in mobile commerce. Information \& Management, 43(8), 950-963. doi:10.1016/j.im.2006.08.009

Doney, P. M., \& Cannon, J. P. (1997). An Examination of the Nature of Trust in Buyer-Seller Relationships. Journal of Marketing, 61(2), 35-51. doi:10.2307/1251829

Economist Online. (2012, April 23). A cut above: Who has the most plastic surgery? Retrieved February 6, 2013, from http://www.economist.com/blogs/graphicdetail/2012/04/daily-chart-13

Eysenbach, G., Diepgen, T. L., Gray, J. A. M., Bonati, M., Impicciatore, P., Pandolfini, C., \& Arunachalam, S. (1998). Towards quality management of medical information on the internet: Evaluation, labelling, and filtering of informationHallmarks for quality of informationQuality on the internetAssuring quality and relevance of internet information in the real world. BMJ (Clinical Research Ed.), 317(7171), 1496-1502. doi:10.1136/bmj.317.7171.1496 PMID:9831581

Eysenbach, G., Powell, J., Kuss, O., \& Sa, E. (2002). Empirical studies assessing the quality of health information for consumers on the world wide web: A systematic review. Journal of the American Medical Association, 287(20), 2691-2700. doi:10.1001/jama.287.20.2691 PMID:12020305

Flavián, C., Guinalíu, M., \& Gurrea, R. (2006). The role played by perceived usability, satisfaction and consumer trust on website loyalty. Information \& Management, 43(1), 1-14. doi:10.1016/j.im.2005.01.002 
Fogg, B.J., Soohoo, C., Danielson, D., Marable, L., Stanford, J., Tauber, E.R., (2002). How do people evaluate a web site's credibility? Stanford University, Consumer WebWatch, Sliced Bread Design, LLC.

Fox, S. (2006). Online Health Search 2006. Pew Internet \& American Life Project.

Frederick, D. A., Lever, J., \& Peplau, L. A. (2007). Interest in cosmetic surgery and body image: Views of men and women across the lifespan. Plastic and Reconstructive Surgery, 120(5), 1407-1415. doi:10.1097/01. prs.0000279375.26157.64 PMID:17898621

Global Information. (2012). Asia Medical Tourism Analysis and Forecast to 2015.

Global Spa Summit. (2010). Spas and the Global Wellness Market: Synergies and Opportunities.

Gordon, J. B., Barot, L. R., Fahey, A. L., \& Matthews, M. S. (2001). The Internet as a source of information on breast augmentation. Plastic and Reconstructive Surgery, 107(1), 171-176. doi:10.1097/00006534200101000-00028 PMID:11176620

Guiry, M., \& Vequist, D. G. (2011). Traveling abroad for medical care: U.S. medical tourists' expectations and perceptions of service quality. Health Marketing Quarterly, 28(3), 253-269. doi:10.1080/07359683. 2011.595644 PMID:21815742

Hesse, B. W., Nelson, D. E., Kreps, G. L., Croyle, R. T., Arora, N. K., Rimer, B. K., \& Viswanath, K. (2005). Trust and sources of health information: the impact of the Internet and its implications for health care providers: findings from the first Health Information National Trends Survey. Archives of Internal Medicine, 165(22), 2618-2624. doi:10.1001/archinte.165.22.2618 PMID:16344419

ISAPS. (2011). International Survey on Aesthetic/Cosmetic Procedures Performed in 2011. from http:// www.isaps.org/files/html-contents/Downloads/ISAPS\%20Results\%20-\%20Procedures\%20in\%202011.pdf

Jarvenpaa, S. L., \& Leidner, D. E. (1999). Communication and trust in global virtual teams. Organization Science, 10(6), 791-815. doi:10.1287/orsc.10.6.791

Javo, I. M., \& Sørlie, T. (2009). Psychosocial predictors of an interest in cosmetic surgery among young Norwegian women: A population-based study. Plastic and Reconstructive Surgery, 124(6), 2142-2148. PMID:19952672

Johnston, R., Crooks, V. A., \& Snyder, J. (2012). “I didn’t even know what I was looking for": A qualitative study of the decision-making processes of Canadian medical tourists. Globalization and Health, $8(1)$, 23-34. doi:10.1186/1744-8603-8-23 PMID:22769723

Lunt, N. (2011). Medical Tourism: Treatments, markets and health system implications: A scoping review. OECD.

Markey, C. N., \& Markey, P. M. (2009). Correlates of young women's interest in obtaining cosmetic surgery. Sex Roles, 61(3-4), 158-166. doi:10.1007/s11199-009-9625-5

McDaniel, L., \& Paul, J. H. (2005). Effect of Nutrient Addition and Environmental Factors on Prophage Induction in Natural Populations of Marine Synechococcus Species. Applied and Environmental Microbiology, 71(2), 842-850. doi:10.1128/AEM.71.2.842-850.2005 PMID:15691939

McKnight, D. H., Choudhury, V., \& Kacmar, C. (2002). The impact of initial consumer trust on intentions to transact with a web site: A trust building model. The Journal of Strategic Information Systems, 11(3-4), 297-323. doi:10.1016/S0963-8687(02)00020-3

Metzger, M. J. (2007). Making sense of credibility on the Web: Models for evaluating online information and recommendations for future research. Journal of the American Society for Information Science and Technology, 58(13), 2078-2091. doi:10.1002/asi.20672

Moorman, C., Deshpandé, R., \& Zaltman, G. (1993). Factors Affecting Trust in Market Research Relationships. Journal of Marketing, 57(1), 81-101. doi:10.2307/1252059

Morahan-Martin, J. M. (2004). How Internet users find, evaluate, and use online health information: A crosscultural review. Cyberpsychology \& Behavior, 7(5), 497-510. doi:10.1089/cpb.2004.7.497 PMID:15667044 
Mun, W. K., \& Musa, G. (2012). Medical tourism in Asia. In M. Hall (Ed.), Medical Tourism: The Ethics, Regulation, and Marketing of Health Mobility (pp. 167-186). New York: Routledge.

Nakayama, M., Wan, Y., \& Sutcliffe, N. (2011). How Dependent Are Consumers on Others When Making Their Shopping Decisions? Journal of Electronic Commerce in Organizations, 9(4), 1-21. doi:10.4018/ jeco.2011100101

Nohria, N., \& Eccles, R. (1992). Networks and Organizations: Structure, Form and Action. Boston: Harvard Business School Press.

O'Grady, L., Betel, L., \& Shachak, A. (2010). Sensemaking and Credibility of Health Information in Online Message Forums: A Multi-Method Study Assessing Tagging and Tag Clouds. Paper presented at the 2010 ACM Conference on Computer Supported Cooperative Work.

Painter, K. (2013, January 13). 35\% of Americans ask Dr. Google for medical diagnose. USA Today.

Peppers, D., \& Rogers, M. (1997). Enterprise one to one: Tools for competing the interactive age. New York: Currency Doubleday.

Peppers, D., \& Rogers, M. (1997). Enterprise One to One. New York: Currency.

Petty, R. E., \& Cacioppo, J. T. (1986). The elaboration likelihood model of persuasion. Advances in Experimental Social Psychology, 19(1), 123-205. doi:10.1016/S0065-2601(08)60214-2

Ren, Y., Harper, F. M., Drenner, S., Terveen, L., Kiesler, S., Riedl, J., \& Kraut, R. E. (2012). Building member attachment in online communities: Applying theories of group identity and interpersonal bonds. Management Information Systems Quarterly, 36(3), 841-864.

Shankar, V., Urban, G. L., \& Sultan, F. (2002). Online trust: A stakeholder perspective, concepts, implications, and future directions. The Journal of Strategic Information Systems, 11(3), 325-344. doi:10.1016/ S0963-8687(02)00022-7

Silberg, W. M., Lundberg, G. D., \& Musacchio, R. A. (1997). Assessing, controlling, and assuring the quality of medical information on the Internet. Journal of the American Medical Association, 277(15), 1244-1245. doi:10.1001/jama.1997.03540390074039 PMID:9103351

Sillence, E., Briggs, P., Fishwick, L., \& Harris, P. (2004). Trust and mistrust of online health sites. Paper presented at the SIGCHI conference on Human factors in computing systems. doi:10.1145/985692.985776

Sillence, E., Briggs, P., Harris, P. R., \& Fishwick, L. (2007). How do patients evaluate and make use of online health information? Social Science \& Medicine, 64(9), 1853-1862. doi:10.1016/j.socscimed.2007.01.012 PMID: 17328998

Sirdeshmukh, D., Singh, J., \& Sabol, B. (2002). Consumer Trust, Value, and Loyalty in Relational Exchanges. Journal of Marketing, 66(1), 15-37. doi:10.1509/jmkg.66.1.15.18449

Smith, A. K. (2012). Health care bargains abroad. Kiplinger's Personal Finance, 66(1), 65-68.

Terry, N. (2007). Under-Regulated Healthcare Phenomena in a Flat World: Medical Tourism and Outsourcing. Western New England Law Review, 29, 421-472.

Torpy, J. M., Burke, A. E., \& Golub, R. M. (2011). Health Literacy. Journal of the American Medical Association, 306(10), 1158-1158. doi:10.1001/jama.306.10.1158 PMID:21917587

Venkatesh, V., Morris, M. G., Davis, G. B., \& Davis, F. D. (2003). User acceptance of information technology: Toward a unified view. Management Information Systems Quarterly, 27(3), 425-478.

Yee, N., Bailenson, J. N., \& Ducheneaut, N. (2009). The Proteus effect implications of transformed digital self-representation on online and offline behavior. Communication Research, 36(2), $285-312$. doi: $10.1177 / 0093650208330254$

Yu, J. Y., \& Ko, T. G. (2012). A cross-cultural study of perceptions of medical tourism among Chinese, Japanese and Korean tourists in Korea. Tourism Management, 33(1), 80-88. doi:10.1016/j.tourman.2011.02.002 
Zhang, J., Seo, S., \& Lee, H. (2013). The impact of psychological distance on Chinese customers when selecting an international healthcare service country. Tourism Management, 35(0), 32-40. doi:10.1016/j. tourman.2012.05.007 